\title{
METHODOLOGICAL FRAMEWORK TO INTEGRATE SOCIAL AND PHYSICAL VULNERABILITY IN THE PREVENTION OF SEISMIC RISK
}

\author{
LUIS IZQUIERDO-HORNA \& RAMZY KAHHAT \\ Department of Engineering, Pontificia Universidad Católica del Perú, Peru
}

\begin{abstract}
The huge variety of natural disasters that have occurred in Peru highlights the necessity, due to the social, economic and environmental impacts, to improve national risk and disaster management plans. Hence the need to evaluate vulnerability from a multidimensional perspective that allows the assessment of the social and physical conditions of the region. The main objective of this research is to help improve risk and disaster management plans by proposing a methodology that integrates the assessment of physical vulnerability (based on the physical characteristics of the infrastructure) with social vulnerability, as a result of the main sociodemographic variables. Using the Peruvian city of Chiclayo (located in the district of Chiclayo) as a case study, this methodology has been implemented for the specific case of earthquakes. In order to determine the overall vulnerability of this district, it was first necessary to determine each component, social and physical, separately. For the physical aspect of vulnerability, the amount of debris generated after a seismic event was used as a proxy. For the social aspect, representative and valid social indicators were used for the study area, such as level of education, age profile, permanent disability. By integrating both results, we obtain a global perspective on the vulnerability, giving equal importance, in the assessment of seismic risk, to the individual and infrastructure. The final result of this methodological tool is identification of which sectors need immediate help after a seismic event. Otherwise, if the seismic risk assessment is based only on information about physical aspects, certain areas of the district, that require urgent actions, may be neglected. Finally, this methodology is applicable for the different scales of analysis (e.g. country, region and district).
\end{abstract}

Keywords: social vulnerability, physical vulnerability, risk and disaster management, social indicators.

\section{INTRODUCTION}

Peru is a country naturally exposed to physical, material and patrimonial damage due to its geographical location. The country is located within the well-known "Pacific Ring of Fire", prone to earthquakes and subsequent large-scale tsunamis [1]. Historically, the Peruvian coast has experienced destructive earthquakes followed by large tsunamis [2]. Given this history, application of preventive risk management measures, as well as the strengthening of plans to mitigate impacts and create a resilient culture is appropriate [2].

In this context, the combination of hazard with the reaction of people led to the development of new concepts that help explain risk in a better way: exposure and vulnerability. The former refers to the potential of a community to suffer losses due to the variability of natural events in a given location; the latter reflects certain characteristics or circumstances that make a system susceptible to the effects of a natural event [3]. Moreover, for Smith and Petley [4], vulnerability reflects the level of social and economic tolerance to such hazardous events in one place.

The concept of vulnerability is of particular relevance in matters of risk and disaster management. However, there is no single definition of this risk factor [5]. One of the bestknown definitions of vulnerability was formulated by the International Strategy for Disaster Reduction (ISDR), which considers vulnerability as a process or conditions governed by external and internal factors that increase the propensity of a community to be impacted 
by natural events [6]. This concept was later complemented by the perspective proposed by the United Nations Development Program (UNDP), which suggested the inclusion of the human process in the assessment of the seismic risk [7]. In both approaches, vulnerability is broken down into two different but complementary aspects: physical and social vulnerability [8]. Physical vulnerability is defined as the damage to infrastructure and is quantified to determine the levels of potential losses [5]. Similarly, social vulnerability focuses on the propensity of a community or individual to suffer damage or experience losses due to natural disasters. Social differences, characterized in a variety of forms in social structures, is the core of social vulnerability [4], [9].

Physical vulnerability is recurrently evaluated around the world and is related to the physical hazard determined for the particular area, which varies due to site characteristics, year of building construction, predominant material, intensity of the event, etc. For example, García-Torres et al. [10], and Mesta et al. [11] quantified and characterized the debris generated after a seismic event of considerable magnitude allowing to estimate, as a proxy, the physical vulnerability associated with the studied cities, Tacna and Chiclayo, respectively.

Nevertheless, the social component of vulnerability is underdeveloped from the theoretical-practical level [12], in part because the social dimension is more difficult to quantify. For instance, when analyzing social vulnerability, many variables require attention and are difficult to quantify. They include the level of exposure and fragility suffered by human groups [13], their degree of preparation [14], the response of people to natural disasters, and other social characteristics of the affected population. Moreover, in one of the proposals made by Cutter [15], social vulnerability is understood as an identification of the social characteristics of the population and how those factors affect the distribution of risks and losses. Also, in another study she mentioned that it can also be considered as the response and bio-social manifestation of the community, which is closely related to the resilience of the sector analyzed [16]. This proposal is relevant when evaluating the social vulnerability as personal factor; that is, without taking into account other situations that may arise. To avoid this impasse, Birkmann [8] adapted and improved the concepts.

Although the traditional engineering perspective on vulnerability focused on physical aspects, the current debate regarding vulnerability clearly underlines the need to take into account various issues and parameters that shape and generate vulnerability, such as the physical, economic, social, environmental and institutional. This implies that the focus of attention has changed from an analysis of physical structure to a broad interdisciplinary analysis of the multidimensional concept of vulnerability. In Birkmann's research [8], the proposed concept emphasizes the fact that vulnerability is a multifaceted component that not only captures Cutter's suggestions [15], but also the capacity for adaptation, and exposure and interaction with disturbances and stress. This broadens the concept of vulnerability to a multi-factored structure that includes exposure, sensitivity, susceptibility, coping capacity, adaptation and response. Therefore, in order to contribute to the improvement of risk management plans and loss mitigation strategies, this research will study in greater depth the concept and implications of vulnerability to natural geological events.

This study describes a methodological proposal based on the vulnerability approach proposed by Birkmann [8] that permits incorporation of the social aspect of vulnerability to the current form of evaluation considering the time and scale of analysis. The article is divided into five sections. The following section provides information about the methodology, in which geographic information system data and statistical calculations are combined to achieve the objective of this work. In addition, important characteristics of the case study (district of Chiclayo) are presented. Section three describes the main findings 
related to the application of this methodology. Then we discuss the most relevant results of this project and present our conclusions, in the final section.

\section{METHODOLOGY}

This section presents a description of the methodology, case study and sources of information used in this investigation. The methodological framework is reflected in Fig. 1 and is explained in the following paragraphs. In sum, the first subsection details the social indicators that are initially identified and classified, based on the intrinsic characteristics of the district and the target community. The second subsection, analysis of social vulnerability, details the gathering of a series of sources of information required for the assessment. At this point, the social assessment categories have been already generated. Next, the social vulnerability information layers are quantified for each specific category. This is when the geo-referenced information system is implemented to store and manage geo-spatial information related to the socially vulnerable sectors. Then, previously obtained layers are incorporated with the physical vulnerability data. For the case study, work done by Mesta et al. [11] will be used. Finally, an integral evaluation of the vulnerability to seismic events is provided.

\subsection{Description of the case study}

For this case study, Chiclayo, a district located in the north of Peru and with a population of around 292,000 inhabitants was selected [17]. This district was chosen because of its socioeconomic role in the national context; the availability of data for the evaluation of physical vulnerability and its high level of seismic risk. In addition, Chiclayo has a high level of seismic vulnerability due to the poor quality of housing construction and the social structure of its population [17]. The location and spatial characteristics of the district are shown in Fig. 2.

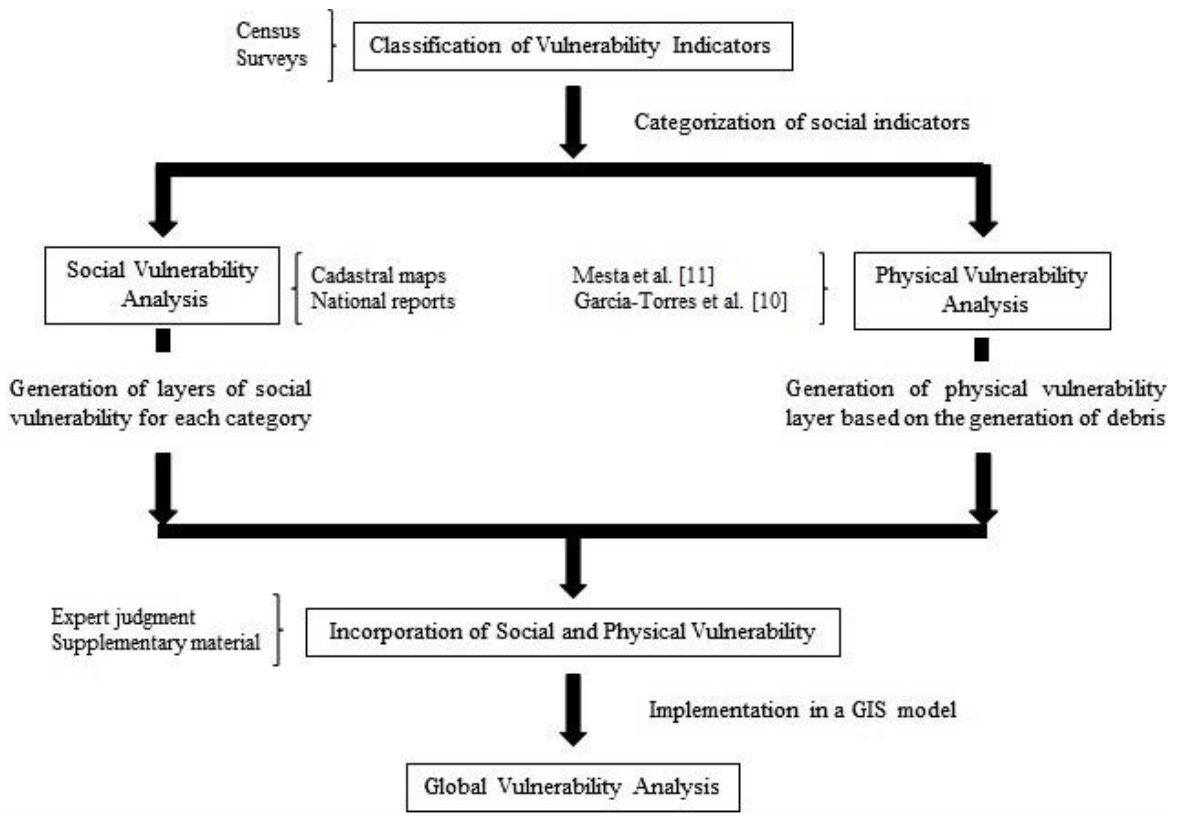

Figure 1: Methodological framework. GIS = geographical information systems. 


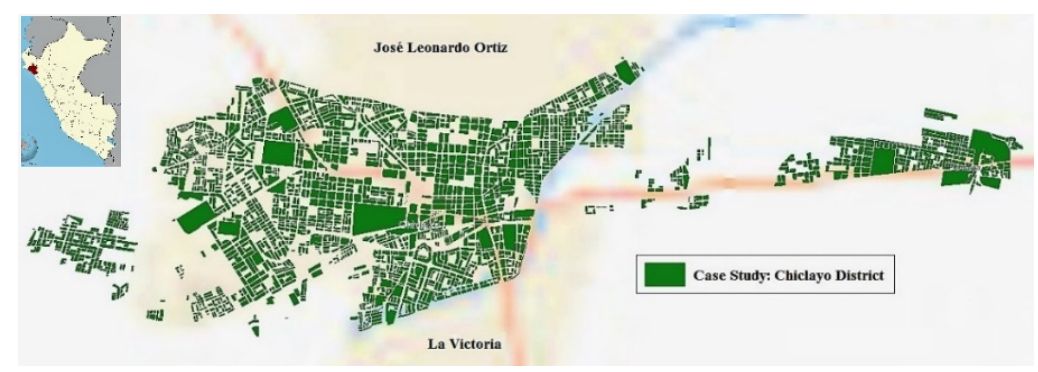

Figure 2: Case study: Chiclayo District, Peru.

\subsection{Classification of social indicators}

Social vulnerability has largely been ignored by governmental decision makers, in part, due to the fact that it is difficult to measure. This explains the absence of the social loss data in the final cost/loss estimate reports, developed by governmental agencies after the occurrence of natural disasters [18]. Due to this, social vulnerability is often described using individual characteristics of people [12] and the surrounding environment [8]. These characteristics are quantitative or qualitative indicators defined according to the characteristics of the case study. They have different meanings and can be observed through time and space [19]. Moreover, it is important to address attributes associated with these indicators, such as validity, sensitivity, robustness, reproducibility, availability, feasibility, simplicity and relevance [8]. One of the most important is validity, since it explains whether an indicator is representative or not of the dimension that is being measured.

As shown in Fig. 3, the initial step of this methodology relates to the clear definition of the objectives and scope of the indicators, essential in the determination of the scale of evaluation and the discrimination capacity of the social indicator. Then, depending on the relevant social characteristics that will be measured, social indicators for the study area are identified and classified. Moreover, after analyzing the results of the selected indicators the behavior of the indicator should be evaluated [8]. The selected indicator will serve to develop the Social Vulnerability Index (SVI).

Despite one of the criticisms with repercussions regarding this evaluation method is the lack of data on some variables, these variables help to improve emergency plans, maps and establish priorities, making them an important tool for decision making [12].

Finally, representative and valid indicators from different sectors were examined to obtain a clearer measure of the situation of the population potentially prone to experiencing damage.

The selected indicators show a great capacity for classification among the various sectors of the area of interest. These classifications are necessary to carry out a vulnerability assessment, since it will allow us to identify with the maximum possible precision the areas that merit priority attention. These social indicators were grouped into four categories to give them greater weight.

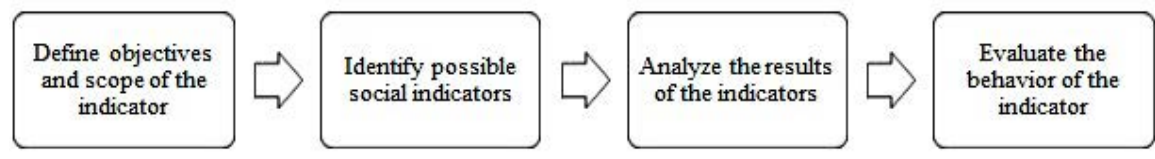

Figure 3: Selection of social indicators [8]. 
Table 1 shows the synergy among the selected indicators. The purpose of this classification is to provide more weight to each category with respect to the vulnerable condition. For example, for the sector related to government conditions, the indicators will show how closely the interests of the government are associated with those of civil society; that is, it will show the levels of perception of the actions of the government leaders, as well as the various actions or measures taken to prevent natural disasters.

Once the social indicators have been identified and classified, the analysis is carried out, taking into account all the corresponding limitations and always bearing in mind that the evaluation carried out is of a dynamic nature and is only valid for the study area in a given period of time.

\subsection{Analysis of social vulnerability}

To address the challenge of analyzing and geographically representing the social vulnerability of the area of interest, researchers have adopted different methodological approaches to characterize vulnerability. In this context, the most used methodology for the evaluation of social indicators is the one proposed by Cutter et al. [18], which focuses on examining the components of social vulnerability. In this methodological framework, the risk interacts with the mitigation in order to obtain the potential hazard. Moreover, the potential hazard is conditioned by the geographical characteristics and the social condition of the place. The latter refers to the community's experience with hazards and its ability to respond and adapt to them. Data sources, both primary (e.g. surveys), and secondary (e.g. census) are vital at this stage. In addition, for the case study, the information used for the assessment of social vulnerability is based on the simulation of data sets through statistical programs. Then, a statistical analysis of this data is carried out in order to determine the score for each of the indicators and thus to elaborate an SVI.

Table 1: Classification of indicators according to validity and representation.

\begin{tabular}{|c|c|c|}
\hline Categories & Abbreviation & Social indicators \\
\hline \multirow{2}{*}{$\begin{array}{l}\text { Vulnerability Level due to } \\
\text { Government Conditions }\end{array}$} & \multirow[b]{2}{*}{ VLGC } & Perception of corruption (PC) \\
\hline & & $\begin{array}{l}\text { Existence of risk management plans } \\
\text { (EMP) }\end{array}$ \\
\hline \multirow{5}{*}{$\begin{array}{l}\text { Vulnerability Level due to } \\
\text { Socio-economic Conditions }\end{array}$} & \multirow{5}{*}{ VLSC } & Dependent population (DP) \\
\hline & & Personal daily income (PDI) \\
\hline & & Level of education (LE) \\
\hline & & Age profile (AP) \\
\hline & & Permanent disability (PD) \\
\hline \multirow{3}{*}{$\begin{array}{l}\text { Vulnerability Level due to } \\
\text { Demographic Conditions }\end{array}$} & \multirow{3}{*}{ VLDC } & $\begin{array}{l}\text { Access to basic medical services } \\
\text { (ABS) }\end{array}$ \\
\hline & & Anthropogenic activity (AA) \\
\hline & & Family structure (FS) \\
\hline \multirow{4}{*}{$\begin{array}{l}\text { Vulnerability Level due to } \\
\text { Comprehension of the Threat }\end{array}$} & \multirow{4}{*}{ VLCT } & Perception of the individual (PI) \\
\hline & & Historical knowledge (HK) \\
\hline & & $\begin{array}{l}\text { Perception of environmental pollution } \\
\text { (PEP) }\end{array}$ \\
\hline & & Community response $(\mathrm{CR})$ \\
\hline
\end{tabular}


Similarly, a study has assessed social vulnerability based on information collected by the government [20]. This type of methodology focuses on exploring the social vulnerability reveal by census data to later elaborate an SVI. The variables analyzed are more general and depend exclusively on the parameters collected in the survey. This methodology is static and is focused on social causes.

The final product, regardless of the method used, must be an SVI. In sum, this SVI is based on the socio-economic and demographic profile of the various communities. It provides a comparative level of measurement of social vulnerability to natural threats [13]. With this tool, it is possible to determine the vulnerability levels of each locality and build a map of social vulnerability. The methodology proposed by Cutter et al. [18] was selected and applied to this study.

\subsection{Analysis of physical vulnerability}

Most researchers work on physical vulnerability, rather than social aspects when assessing vulnerability related to seismic events. The methodological framework developed by GarcíaTorres et al. [10] to calculate the generation of debris after a seismic event is recommended in this proposed methodology in order to address the physical vulnerability. Moreover, debris generation is recommended as a proxy to quantify physical vulnerability. For example, if area $\mathrm{A}$ is calculated to produce more tons of debris generated than area $\mathrm{B}$, then area A will be classified as more vulnerable than area B. In addition, for the case study, the work done by Mesta et al. [11] in Chiclayo has been used to provide data. Although, different scenarios were modeled in this paper, the scenario corresponding to Mw 7.4 seismic event was chosen for the current study.

\section{RESULTS}

This section describes the main findings of this article. First, results about the layers of social vulnerability in their different categories are presented. Second, results related to the layer of physical vulnerability as characterized by the generation of debris are discussed. They were obtained from work done by Mesta et al. [11].

\subsection{Social vulnerability}

As a result of the statistical analysis, four layers (i.e. Government Conditions, Socioeconomic Conditions, Demographic Conditions, and Comprehension of the Threat) were determined in order to show the most vulnerable area in Chiclayo. These layers are aggregated into categories that represent the main characteristics of the community.

It has been observed that parts of Chiclayo are dynamic, in which live different groups of people. We can see in these layers that the levels of the indicators analyzed are not different, indicating that some areas share similar trends of vulnerability. In the case of the socio-economic conditions, it is possible to conclude that there is a correlation with demographic conditions. That makes sense because households of high status can access basic city services, including family planning. This relationship is in both directions. Additionally, it is possible to establish a cause-effect with the layer about Comprehension of the Threat because if a household possesses good levels in the previous factors, they will be able to respond to the natural disaster in the best way instead of being in panic. However, with the government conditions layer, it is not possible establish a pattern because it is more subjective than the others; people affected would always want the government to do more. 

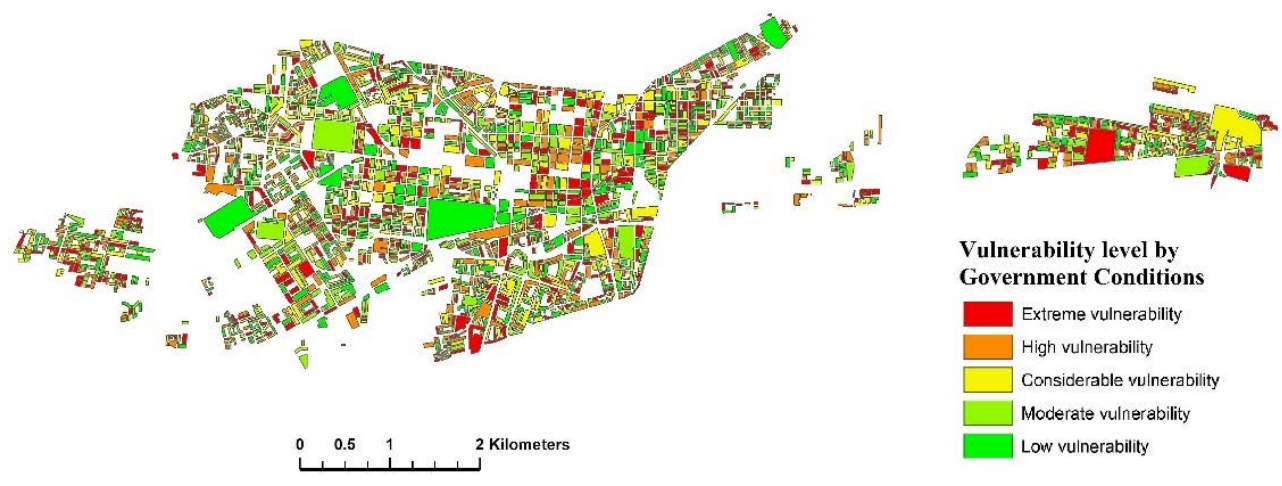

(a)

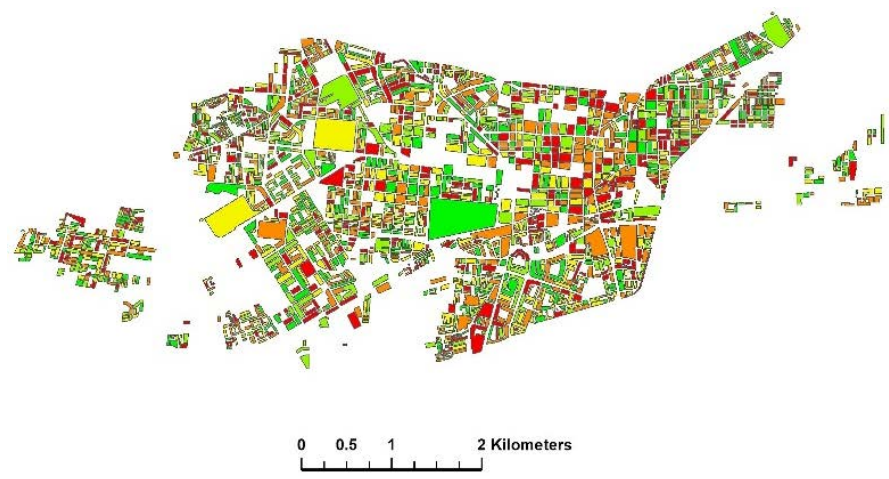

Vulnerability level by Government Conditions

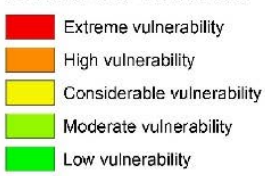

(b)
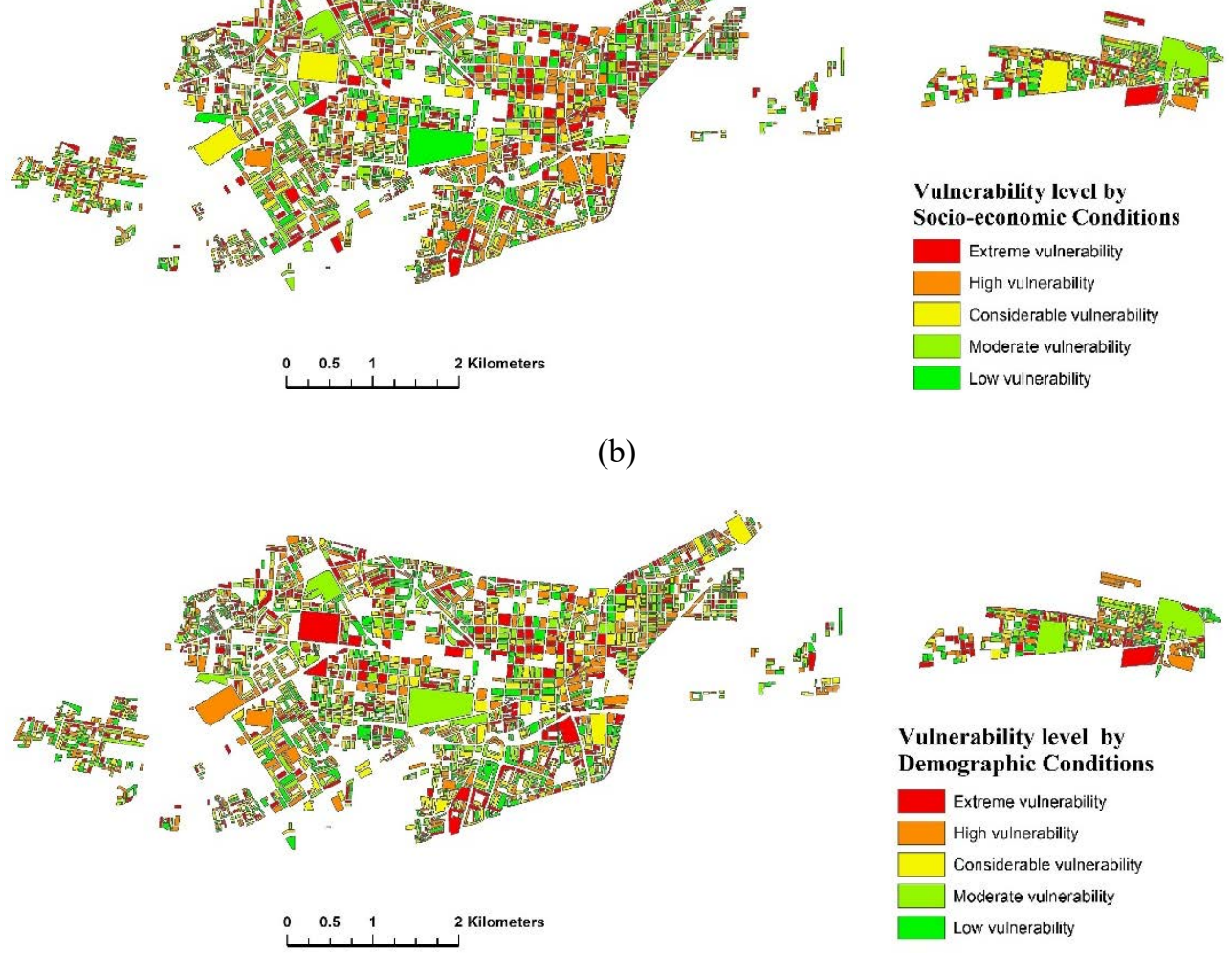

Vulnerability level by Socio-economic Conditions

Extreme vulnerability High vulnerability Considerable vulnerability Moderate vulnerability Low vulnerability

(c)

Figure 4: Social vulnerability layers. (a) Government Conditions; (b) Socio-economic Conditions; (c) Demographic Conditions; (d) Comprehension of the Threat. 

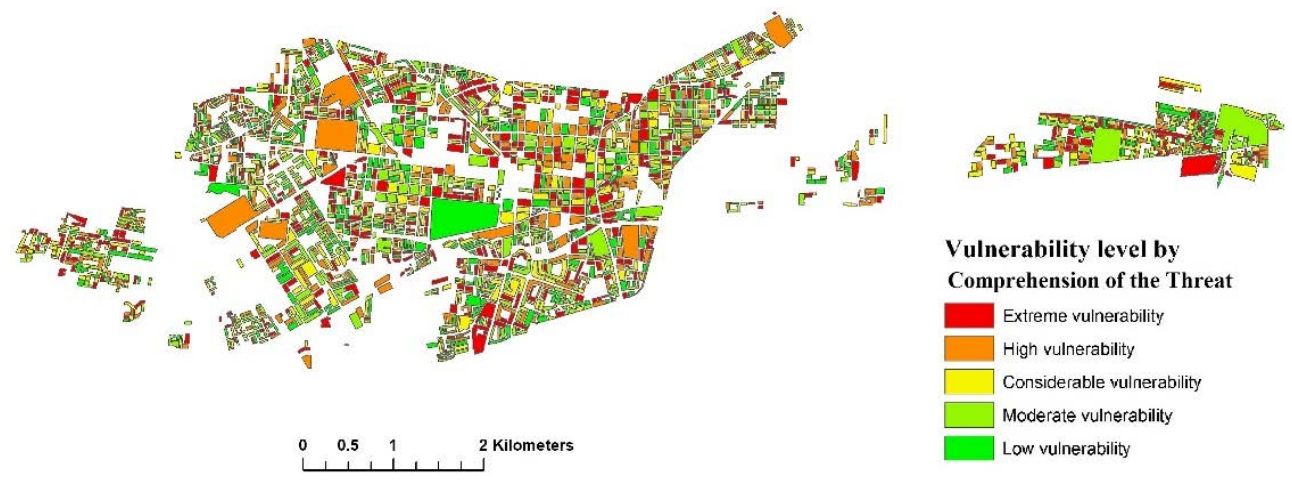

(d)

Figure 4: Continued.

Finally, the results obtained from social vulnerability, independent of category, complement the layer obtained from physical vulnerability. This is because the layer of debris generation only takes into account the infrastructure and not human beings.

\subsection{Physical vulnerability}

According to the results generated by Mesta et al. [11], it is possible to generate a layer that shows the level of the physical vulnerability (i.e. extreme, high, considerable, moderate and low) in Chiclayo. This layer focused on identifying the possible sectors that will suffer damage due to a seismic event.

In addition, it is possible to observe that the eastern zone of Chiclayo is more vulnerable because it is calculated to generate more debris after a seismic event. Similarly, the central and western zones generate less debris, thus having a lower level of vulnerability in those sectors.
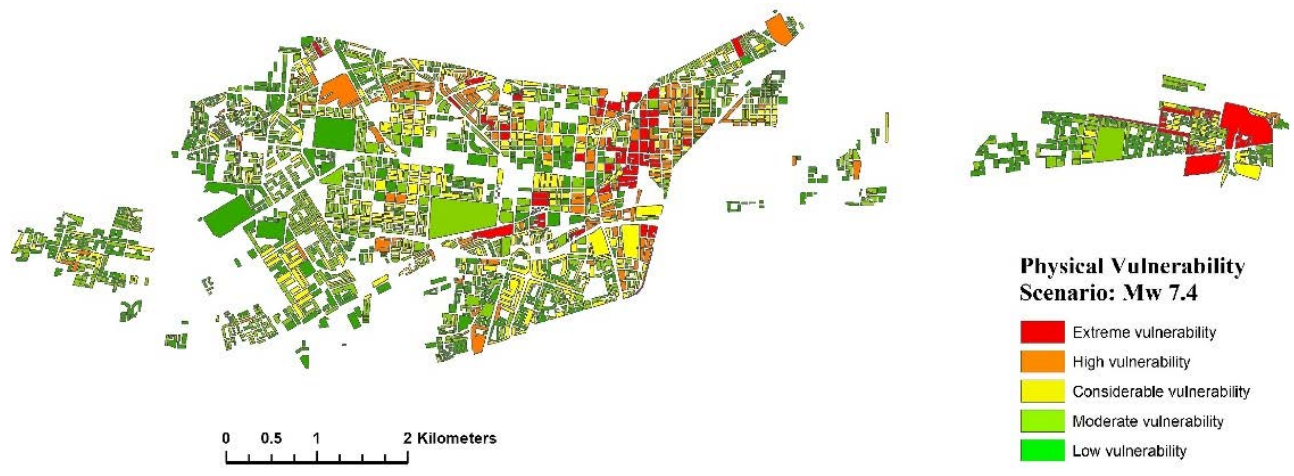

Figure 5: Physical vulnerability [11]. 


\section{DISCUSSION}

The significance of the evaluation of social vulnerability is discussed because it is a fundamental tool in the preparation of emergency plans and risk management. In fact, a mapping of vulnerability can provide an overview of the areas where the social structure is important at the time of response, preparation and recovery from a disaster. Identifying and understanding social indicators are relevant to determine which group is most vulnerable so as to be able to identify and implement the appropriate corrective measures. It is necessary to mention that the most vulnerable areas are not easy to predict by a single indicator; therefore, it is necessary to combine different socio-economic, demographic, and governmental aspects, among others.

Moreover, it is important to evaluate how accumulated social vulnerability changes over time and space. On the other hand, it is necessary to investigate the best way to combine social and physical vulnerability to obtain a much more complete and reliable mapping of vulnerability. It is of particular interest to note that the methodology presented in this paper can be applied in different localities, taking into consideration the type of disaster, and the information and resources available. Finally, the development and integration of social concerns with the natural environment and natural disasters will improve the evaluation of hazards and allow prioritization among communities and vulnerable groups.

From the aspects analyzed, four layers of vulnerability were obtained, involving the following aspects: socio-economic, demographic, comprehension of the threat and governmental conditions. Each of them shows a degree of vulnerability based on the indicators that characterize them. From the layers obtained, some relationships can be obtained directly. For example, for an area whose vulnerability is conditioned by the demographic factor is indicated to be medium-high, the layer related to the threat share similar patrons. This is because each indicator adequately measures the corresponding dimension. For example, if one of the indicators of demographic sector is the family structure, then having more family members will increase the vulnerability of the target group.

Finally, the relationships between the layers of physical and social vulnerability show differences with regard to what should be the priority for attention. Due to this, it is necessary to carry out an integral evaluation of both the physical and the social components to obtain a general perspective on the reality of the analyzed sector.

\section{CONCLUSIONS}

In this article, a multidimensional perspective of vulnerability was used to study this risk factor. The assessment was divided into two categories: physical vulnerability and social vulnerability. The first one was based in the work done by Mesta et al. [11], while the latter was based on data sets generated using a Monte Carlo Simulation. Application of the proposed methodology consisted of the selection of social indicators in order to elaborate an SVI. Results indicate that the mixture of social and physical vulnerability generates a robust local mapping of vulnerability to seismic events.

This analysis is important because it allows identification of the area(s) requiring immediate attention based on social and physical vulnerability. Incorporation of social vulnerability into the analysis of seismic risk is an important step in developing more holistic and accurate risk and disasters management plans.

Another important point is that in Peru, all management plans are based on the response of buildings to a seismic event and do not meet the main objective of public policies, which focus on human well-being. 
Finally, the local mapping of vulnerability that would result if this methodology is applied, would allow identification of administrative failures based on mitigation plans, emergency strategies, censuses, information gathering, etc.

\section{ACKNOWLEDGEMENTS}

This project was partially funded by CONCYTEC, within the framework of the 232-2015FONDECYT Agreement. The authors would like to thank Joshua Wolfe for his valuable comments on the previous version of this manuscript.

\section{REFERENCES}

[1] Yauri, S., Escenario Sísmico para Lima Metropolitana y Callao: Sismo 8.8 Mw, INDECI - DIPRE: Lima, 2017.

[2] Morales-Soto, N. \& Zavala, C., Terremotos en el Litoral Central del Perú: ¿Podría ser Lima el Escenario de un Futuro Desastre? Rev. Perú Salud Publica: Lima, pp. 217-224.

[3] Rubiños, A. \& Tarque, N., Vulnerabilidad Sísmica, PUCP: Lima, 2017.

[4] Smith, K. \& Petley, D., Environmental Hazards: Assessing Risk and Reducing Disaster, Routledge: New York, 2009.

[5] Birkmann, J., Kienberger, S. \& Alexander, D., Assessment of Vulnerability to Natural Hazards: A European Perspective, Elsevier: China, 2014.

[6] ISDR, Living with Risk: A Global Review of Disaster Reduction Initiatives, UN: Geneva, 2004.

[7] UNDP, Reducing Disaster Risk: A Challenge for Development. A Global Report, BRCP: New York, 2004.

[8] Birkmann, J., Measuring Vulnerability to Promote Disaster-Resilient Societies: Conceptual Frameworks and Definitions, UNU: Hong Kong, 2006.

[9] Thomas, D. \& Phillips, B., Social Vulnerability to Disasters, CRS Press: Boca Raton, 2009.

[10] García-Torres, S., Kahhat, R. \& Santa-Cruz, S., Methodology to characterize and quantify debris generation in residential buildings after seismic events. Resources, Conservation and Recycling, 117, 2016.

[11] Mesta, C., Kahhat, R. \& Santa-Cruz, S., Quantification of lost material stock of buildings after an earthquake. A case study of Chiclayo, Perú. Proceedings of World Conference on Earthquake, Santiago de Chile, 2017.

[12] Cutter, S., Vulnerability analysis for environmental hazards. Encyclopedia of Quantitative Risk Analysis and Assessment, pp. 1941-1952, 2008.

[13] Bohórquez, J.T., Evaluación de la vulnerabilidad social ante amenazas naturales en Manzanillo. Un Aporte de Método, Boletín del Instituto de Geografía, UNAM, 81, pp. 79-93, 2013.

[14] Cannon, T., Vulnerability analysis and the explanation of 'natural' disasters. Development and Environment, ed. A. Varley, John Wiley \& Sons, pp. 13-29, 1994.

[15] Cutter, S., Measuring and Mapping Social Vulnerability, Bangkok, 2009.

[16] Cutter, S., Barnes, L., Berry, M., Burton, C., Evans, E., Tate, E. \& Webb, J., A placebased model for understanding community resilience to natural disasters. Global Environmental Change, 18(4), pp. 598-606, 2008.

[17] Instituto Nacional de Estadística e Informática (INEI), www.inei.gob.pe/. Accessed on: 18 Feb. 2018.

[18] Cutter, S., Boruff, B. \& Lynn, S., Social vulnerability to environmental hazard. Social Science Quarterly, 84, pp. 242-261, 2003. 
[19] Frigerio, I. \& Amicis, M., Mapping social vulnerability to natural hazards in Italy: a suitable tool for risk mitigation strategies. Environmental Science \& Policy, 63, pp. 187-196, 2016.

[20] Armas, I. \& Gavris, A., Census-based social vulnerability assessment for Bucharest. Procedia - Environmental Sciences, 32, pp. 138-146, 2016. 